\title{
ANÁLISE DE ASPECTOS HIDROLÓGICOS DAS SUB-BACIAS DO PARNAÍBA E ITAPECURU EM TIMON, MA
}

\section{Analysis of aspects hydrological of the Parnaíba and Itapecuru sub-basins in Timon, MA}

\author{
Tiago Rodrigues da Silva \\ Graduação em Licenciatura em Ciências Biológicas pelo IFMA, Timon. \\ thiago2581@hotmail.com \\ Cristiano Jackson da Costa Coelho. \\ Doutor em Biotecnologia e Docente do Instituto Federal do Maranhão, Campus Timon \\ crisjcc@ifma.edu.br
}

\begin{abstract}
RESUMO: O presente trabalho objetivou dimensionar e analisar os volumes de interceptação, evapotranspiração, infiltração e escoamento superficial nas sub-bacias dos rios Parnaíba e Itapecuru localizadas no município de Timon, Maranhão, Brasil. O uso e ocupação do solo e suas relações com a cobertura vegetal foram os principais parâmetros utilizados para a interpretação dos dados. Para tanto, foram utilizadas metodologias para estudos básicos em hidrologia aplicados a pequenas bacias hidrográficas. Os resultados mostram que os volumes totais de interceptação $(0,37221 \mathrm{~km} 3 / \mathrm{ano})$, evapotranspiração $\left(0,47760 \mathrm{~km}^{3} / \mathrm{ano}\right)$, infiltração $(0,00178 \mathrm{~km} 3 / \mathrm{ano})$ e escoamento superficial $(1,55857$ $\mathrm{km}^{3} / \mathrm{ano}$ ) das sub-bacias do Itapecuru e Parnaíba são diretamente influenciados pelo grau de cobertura vegetal. Os comportamentos hidrológicos em ambas as sub-bacias ocorrem de maneira similar nas unidades de paisagem de vegetação e solo exposto. No entanto, há a distinção do uso e ocupação em uma área urbanizada, presente somente na sub-bacia do Parnaíba, exercendo alterações nos processos do ciclo hidrológico.
\end{abstract}

Palavras-chave: Uso e ocupação do solo; Cobertura vegetal; Escoamento superficial.

ABSTRACT: The present study aimed dimension and analyze the volumes of interception, evapotranspiration, infiltration and surface runoff in the sub-basins of the Parnaíba and Itapecuru rivers located in the municipality of Timon, Maranhão, Brazil. The land use and land cover of the soil and its relations with the vegetal cover were the main parameters used for the interpretation of the data. For that, methodologies were used for basic studies in hydrology applied to small hydrographic basins. The results show that the total volumes of interception $\left(0.37221 \mathrm{~km}^{3} / \mathrm{year}\right)$, evapotranspiration $(0.47760$ $\mathrm{km}^{3} /$ year), infiltration $\left(0.00178 \mathrm{~km}^{3} /\right.$ year) and surface runoff $\left(1.55857 \mathrm{~km}^{3} /\right.$ year $)$ the Itapecuru and Parnaíba sub-basins are directly influenced by the grade of vegetation cover. Hydrological behaviors in both sub-basins occur similarly in the landscape units in the vegetation and in the bare soil. However, there is the distinction of land use and land cover in an urbanized area, present only in the sub-basin of Parnaíba, exerting alterations in the processes of the hydrological cycle.

Keywords: Land use and land cover; Vegetation cover; Surface runoff. 
ANÁLISE DE ASPECTOS HIDROLÓGICOS DAS SUB-BACIAS DO PARNAÍBA E ITAPECURU EM TIMON, MA

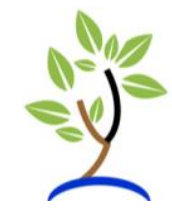

\section{INTRODUÇÃO}

O ciclo da água pode ser definido como seu movimento natural no planeta entre a superfície terrestre e atmosfera através de suas mudanças de estado físico. Sendo impulsionado pela energia solar associada à gravidade e à rotação terrestre, por conseguinte, responsável pela constância da quantidade total de água existente no planeta (PAZ, 2004; PINTO et al., 2008).

O regime hidrológico de uma bacia hidrográfica é fortemente influenciado por suas características físicas, geológicas, topográficas e clima (PAZ, 2008). Para Clarke e Tucci (1997), os fluxos de água durante os processos hidrológicos nas bacias hidrográficas são verticais (etapas de precipitação, interceptação e evapotranspiração) e longitudinais, correspondente ao escoamento na direção dos gradientes da superfície (escoamento superficial e rios) e do subsolo (escoamento subterrâneo).

A precipitação consiste na única forma de entrada de água na bacia hidrográfica (MONTEIRO; SILVA JÚNIOR 2015). O processo de precipitação pode ser entendido como o conjunto de águas que atinge a superfície terrestre, sendo capaz de gerar o escoamento superficial (TUCCl, 2001). Além disso, caracteriza-se por três grandezas: altura pluviométrica, volume da chuva precipitado, duração e intensidade, que visa determinar a sua variabilidade temporal (PINTO et al., 2008).

A interceptação corresponde a retenção da precipitação acima da superfície do solo (BLAKE, 1975). Tal fenômeno ocorre devido a vegetação ou outra forma de obstrução ao escoamento (TUCCI, 2001). A interceptação pela vegetação depende das características da precipitação da região, clima, tipo e densidade da vegetação (PAZ, 2008). Enquanto isso, a evapotranspiração é o fenômeno que considerada a perda de água por evaporação do solo e transpiração dos vegetais (PINTO et al., 2008). O processo envolve a interação entre o solo, vegetação e atmosfera, por meio da qual ocorrem trocas de calor, energia e água (PAZ, 2008).

$\mathrm{O}$ escoamento superficial tem origem na precipitação. Da quantidade de água que atinge o solo na precipitação, parte é retida pela vegetação e depressões de terreno e outra parte é infiltrada (TUCCI, 2001). Quando o solo ultrapassa a sua capacidade de absorver a água, ocorre o escoamento superficial (PINTO et al., 2008). Dessa forma, os fatores climáticos relacionados à intensidade e duração da precipitação, área, permeabilidade e topografia da bacia e obras hidráulicas são fatores que influenciam o escoamento superficial (CLARKE; TUCCI, 1997).

A água que infiltra no solo ocasiona o processo de passagem de água da superfície para o interior do solo (PAZ, 2008). Assim, a capacidade de infiltração varia de acordo com a natureza, porosidade e estado de superfície do solo (PINTO et al., 2008).

Desse modo, o ciclo hidrológico está associado pelas características locais, como clima, relevo, tipo de solo, uso e ocupação do solo, geologia, tipo de cobertura vegetal, rede hidrográfica, etc. (PINTO et al., 2008). Dentre os fatores que influenciam o ciclo hidrológico, neste trabalho foram tratados, essencialmente, o uso e ocupação do solo e suas relações com a cobertura vegetal. Para Paz (2004), estes podem ser o que mais repercutem em alterações no fluxo da água nos processos de interceptação,

REVISTA GEONORTE, V.9, N.33, p.95-110, 2018.

DOI: 10.21170/geonorte.2018.V.9.N.33.95.110

(ISSN 2237 - 1419) 
ANÁLISE DE ASPECTOS HIDROLÓGICOS DAS SUB-BACIAS DO PARNAÍBA E ITAPECURU EM TIMON, MA

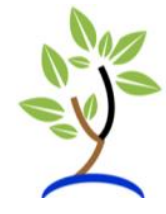

evapotranspiração, infiltração e escoamento superficial, caraterizado como o resultado de todos os processos e etapas do ciclo hidrológico.

O uso do solo é compreendido como as apropriações da massa natural territorial para o desenvolvimento das atividades antrópicas, se relacionando diretamente também com o tipo de cobertura vegetal (VAEZA et al., 2010). Sendo que as ações na prática produzem áreas com cobertura terrestre uniformes nos aspectos biológicos, físicos e químicos nas quais podem ser sistematizadas em classes de unidades de paisagem, que demostram as simultaneidades entre aspectos e impactos ambientais das atividades humanas (LOMBARDI NETO; BERTONI, 2010; SEBUSIANI; BETTINE, 2011).

As unidades de paisagem, portanto, representam o uso e ocupação do solo, o que reflete na sistematização de informações de sua utilização pelo homem ou, quando isso não ocorre a caraterização biótica que se localiza na superfície terrestre (SEBUSIANI; BETTINE, 2011). O fato é que as modificações na cobertura vegetal no uso do solo possuem impactos significativos nos processos hidrológicos nas bacias hidrográficas (CUNHA et al., 2014).

Diante disso, determinar a interceptação, evapotranspiração, infiltração e escoamento superficial constituem-se como um dos primeiros passos para entender 0 funcionamento de uma bacia hidrográfica, bem como para obter resultados que possam subsidiar uma rede de monitoramento e informações hidrológicas.

O presente artigo tem como o objetivo dimensionar e analisar os volumes de interceptação, evapotranspiração, infiltração e escoamento superficial nas sub-bacias hidrográficas dos rios Parnaíba e Itapecuru situadas no município de Timon, Maranhão. Com isso, realizar análises das condições e influências de uso e ocupação do solo perante o comportamento hidrológico das áreas de estudo.

\section{MATERIAIS E MÉTODOS}

\section{Caracterização da área de estudo}

O município de Timon, localizado no Estado do Maranhão, possui uma população estimada em 166.295 habitantes (IBGE, 2017), e ocupa duas sub-bacias hidrográficas: Itapecuru e Parnaíba (Figura 1) correspondendo, respectivamente uma área de $320,7 \mathrm{~km}^{2}$ e 1443,91 Km² (TIMON, 2014). 
ANÁLISE DE ASPECTOS HIDROLÓGICOS DAS SUB-BACIAS DO PARNAÍBA E ITAPECURU EM TIMON, MA

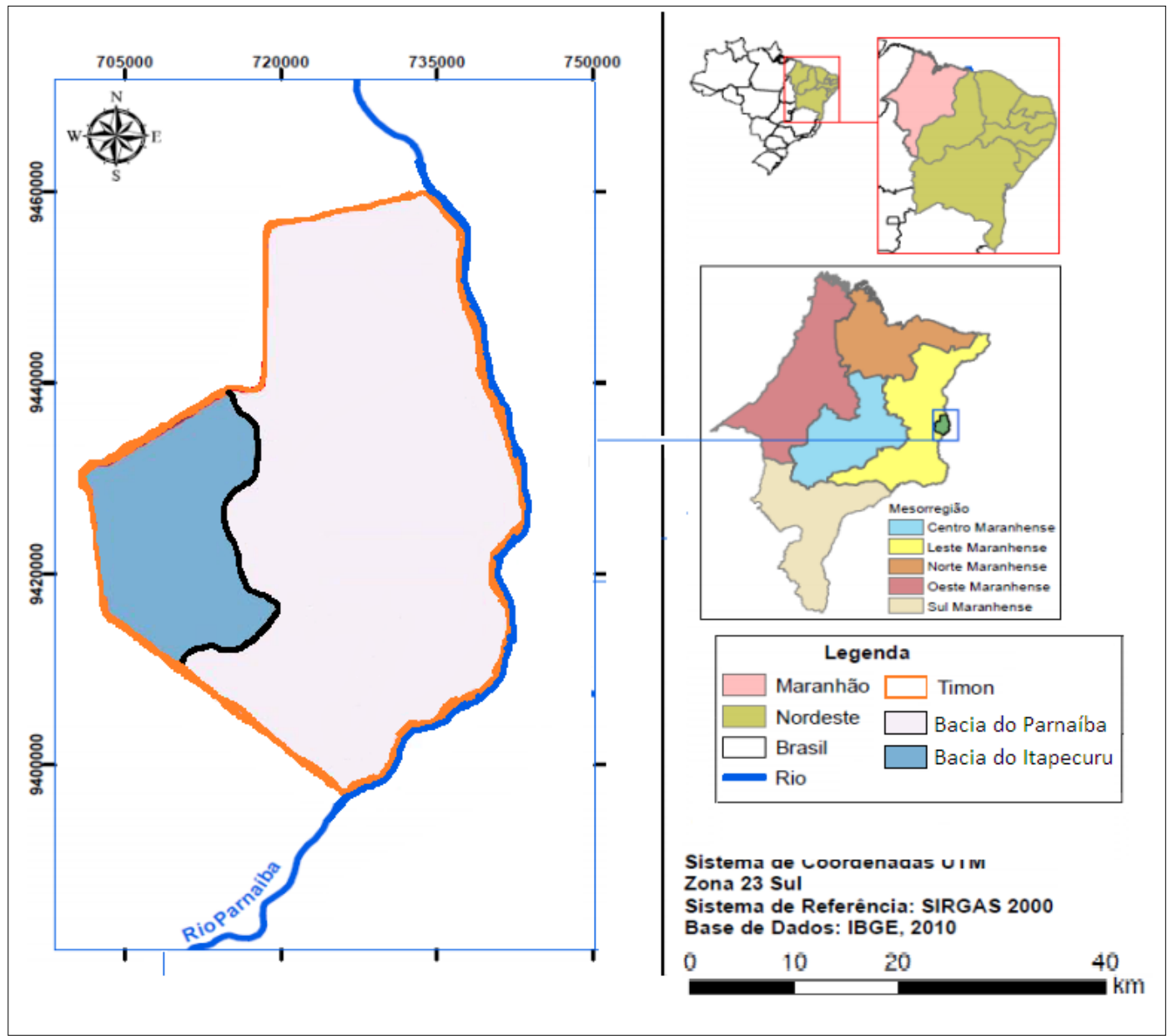

Figura 1: Localização de Timon, MA e de suas bacias do rio Parnaíba e Itapecuru. Fonte: Timon (2014) e Silva (2016), adaptado pelos autores.

A área da sub-bacia do Parnaíba no município faz parte da região hidrográfica de mesmo nome denominada de sub-bacia hidrográfica de número seis. Por sua vez, a área do Itapecuru compõe região hidrográfica Atlântico Nordeste Ocidental com o nível de sub-bacia de número dois (BRASIL, 2015).

O município caracteriza-se por apresentar altitudes ligeiramente próximas a $250 \mathrm{~m}$ acima do nível do mar (TIMON, 2017). Quanto à vegetação, Timon situa-se na faixa transicional da Amazônia, a oeste, a Caatinga, a leste e Cerrado, ao sul (TIMON, 2014).

Segundo a classificação de Köppen, adotada universalmente e adaptada ao Brasil o clima da área de estudo é do tipo sub-úmido seco do tipo (C1), com pouco ou nenhum excesso de água, tem-se dois períodos bem definidos: um chuvoso, de dezembro a maio, e outro seco, nos meses de junho a novembro (TIMON, 2014). Dentro do período de estiagem, a precipitação pluviométrica variou de 1,4 a $29,5 \mathrm{~mm}$ e no período chuvoso, de 11,6 a 291,5 mm, com média anual em torno de $790 \mathrm{~mm}$. Esses dados são referentes ao período de 1961 a 1990 (CORREIA FILHO et al., 2010). A 
ANÁLISE DE ASPECTOS HIDROLÓGICOS DAS SUB-BACIAS DO PARNAÍBA E ITAPECURU EM TIMON, MA

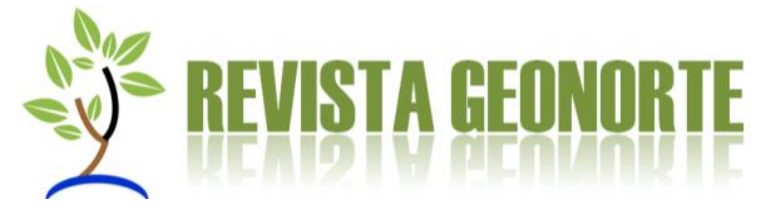

temperatura média ao longo do ano de $27,3^{\circ} \mathrm{C}$ e possui poucas alterações devido à proximidade com a Linha do Equador (TIMON, 2014).

O município de Timon está inserido nos domínios da Bacia Sedimentar do Parnaíba com um relevo formado pela depressão do planalto oriental, que constitui um conjunto de morfoesculturas ao Leste, prolongando-se para o Nordeste do Maranhão (CORREIA FILHO et al., 2010).

A sua pedologia está caracterizada e classificada pelas normas estabelecidas no Sistema Brasileiro de Classificação de Solos com as principais classes e foram identificadas foram as seguintes: Latossolo Amarelo Álico e Distrófico; Argissolo Vermelho-Amarelo Distrófico e Argissolo Vermelho-Amarelo concrecionário; Gleissolos, Neossolo Litólico Eutrófico; Neossolo Quetzarênico Órtico, Plintossolos e Podzólicos (MARQUES, 2015).

\section{Coleta dos dados pluviométricos}

Os dados pluviométricos para a quantificação dos aspectos hidrológicos foram obtidos por meio da estação meteorológica do Aeroporto Petrônio Portela de Teresina, Piauí (TERESINA (AER. PETRONIO PORTELA); Código WMO: 82579; Código ICAO: SBTE; Latitude Sul: -5,03;; Longitude Oeste: -42,82ㅇ; Altitude: 69m) (INMET, 2016). A justificativa para a escola dessa estação decorreu em função da cidade de Timon não possuir sua própria estação meteorológica, bem como ser a mais próxima das áreas de estudo com uma distância de 7,5 km do município.

Assim, obtiveram-se as precipitações médias mensais para o município de Timon nos períodos de 2005 a 2015 com a finalidade de uma série histórica dos últimos dez anos. Tais dados foram coletados no sítio eletrônico do Banco de Dados Meteorológicos para Ensino e Pesquisa (BDMEP) do Instituto Nacional de Meteorologia (INMET) que contém as séries históricas das estações meteorológicas convencionais do país de forma digital (INMET, 2016).

\section{Cálculos dos aspectos hidrológicos}

Nas determinações do escoamento superficial, utilizou-se a metodologia de hidrologia aplicada a pequenas bacias hidrográficas proposta por Alcântara e Santos (2002). Desse modo, o escoamento superficial foi determinado para cada unidade de paisagem através da utilização do mapa de uso e ocupação do solo referente ao ano de 2016 (Figura 2).

Nos cálculos foram consideradas suas respectivas áreas (em hectares) de abrangência nas sub-bacias do Parnaíba e Itapecuru (Tabela 1), calculando por meio da equação (1):

$$
E S=V-d-E T P-I \quad \text { Eq. } 1
$$


ANÁLISE DE ASPECTOS HIDROLÓGICOS DAS SUB-BACIAS DO PARNAÍBA E ITAPECURU EM TIMON, MA

Onde:

$E S=$ Escoamento superficial (m³/ano);

$\mathrm{V}=$ Volume precipitado ( $\left.\mathrm{m}^{3} / \mathrm{ano}\right)$;

$D=$ Infiltração ( $\left.\mathrm{m}^{3} / \mathrm{ano}\right)$;

$\mathrm{ETP}=$ Evapotranspiração potencial (m³/ano);

I = Interceptação ( $\left.\mathrm{m}^{3} / \mathrm{ano}\right)$.

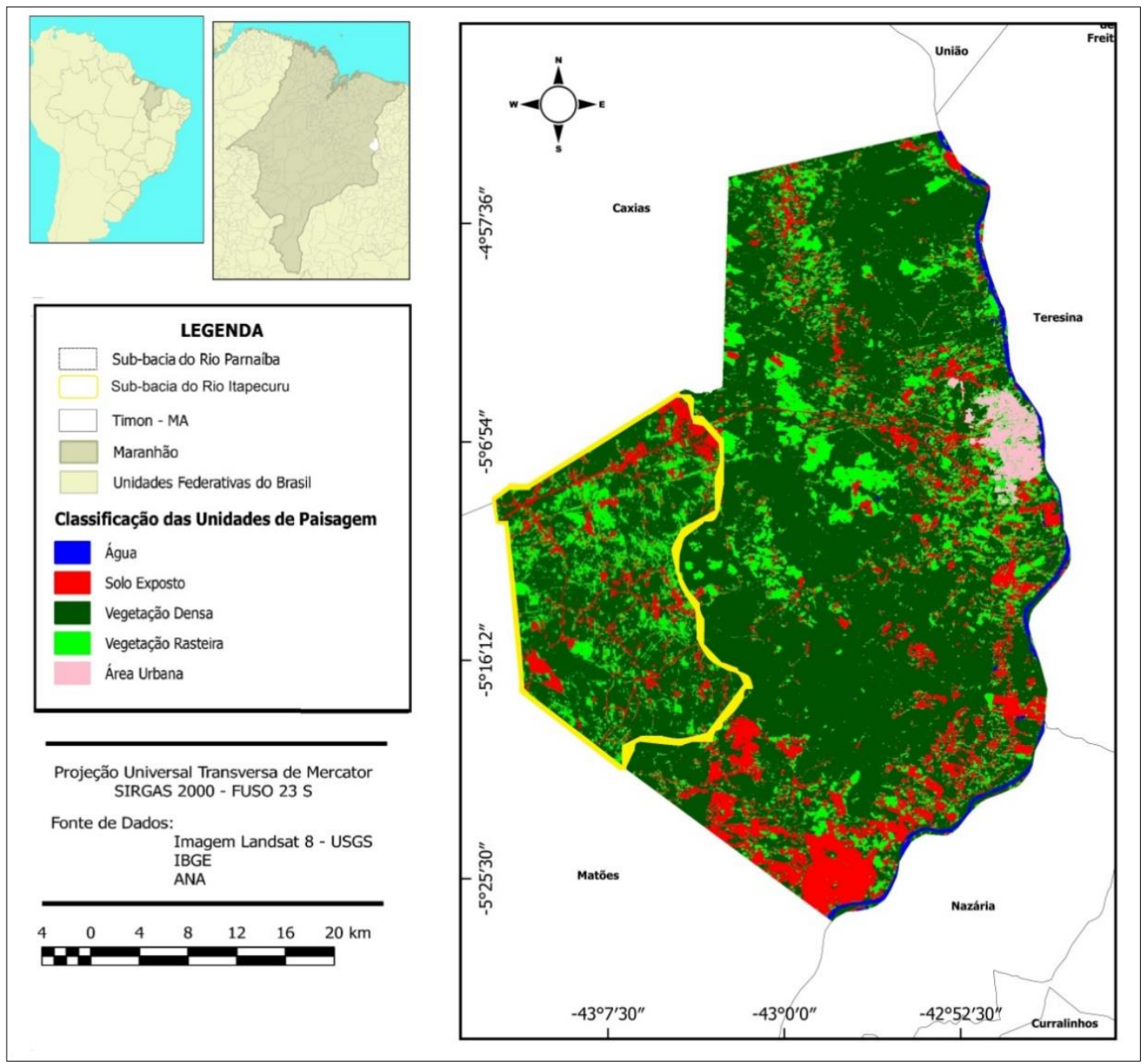

Figura 2: Unidades de paisagem do uso e ocupação do solo das sub-bacias do rio Parnaíba e Itapecuru em Timon/MA em 2016. Fonte: Elaboração dos autores. 
ANÁLISE DE ASPECTOS HIDROLÓGICOS DAS SUB-BACIAS DO PARNAÍBA E ITAPECURU EM TIMON, MA

Tabela 1. Áreas das classes de unidades de paisagem do uso e ocupação do solo das sub-bacias do rio Parnaíba e Itapecuru em Timon, MA

\begin{tabular}{|c|c|c|}
\hline \multirow{3}{*}{ Unidades de Paisagem } & \multicolumn{2}{|c|}{ Sub-bacia hidrográfica } \\
\hline & Parnaíba & Itapecuru \\
\hline & Área (Hectares) & \\
\hline Água & $1.602,00$ & 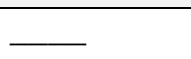 \\
\hline Área Urbana & $2.531,09$ & 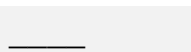 \\
\hline Solo Exposto & $21.214,47$ & $2.866,32$ \\
\hline Vegetação Rasteira & $22.717,12$ & $4.390,20$ \\
\hline Vegetação Densa & $94.153,23$ & $29.861,73$ \\
\hline Total & $142.216,91$ & $37.118,25$ \\
\hline
\end{tabular}

Foram realizados os cálculos dos volumes precipitados nas quais se utilizaram a lâmina de água que é gerada em decorrência da precipitação. Assim, determinaramse os volumes para cada unidade e mês de acordo com a equação (2) de Alcântara e Santos (2002):

$V=A \cdot P$

Eq. 2

Onde:

$\mathrm{V}=$ Volume da unidade de paisagem ( $\left.\mathrm{m}^{3} / \mathrm{mês}\right)$;

$A=$ Área da unidade de paisagem $\left(\mathrm{m}^{2}\right)$;

$\mathrm{P}=$ Precipitação média mensal ( $\mathrm{m} / \mathrm{mês})$.

Posteriormente, efetuaram-se os cálculos de interceptação, utilizando a equação (3) abaixo modificada de Clark (1940):

$$
I=\frac{(\mathrm{V} .(\% \text { UP }))}{100 \%}
$$

Onde:

I = Interceptação de chuva na unidade de paisagem $\left(\mathrm{m}^{3}\right)$;

$\mathrm{V}=$ Volume da unidade de paisagem $\left(\mathrm{m}^{3}\right)$;

UP $($ em \%) = Percentual de retenção da unidade de paisagem. 
A metodologia atribui para cada unidade de paisagem valores em porcentagem que correspondem sua retenção (calibração do modelo). Então, segundo Alcântara e Santos (2002) as porcentagens corresponderam 0,5\% para área urbana; 5\% para solo exposto e área de vegetação rasteira; $20 \%$ para área de vegetação densa.

Ao considerar a evapotranspiração (ETP), conforme Paz (2008), como a quantidade de água transferida para a atmosfera por evaporação e transpiração, na unidade de tempo, de uma área extensa com cobertura vegetal, sua determinação foi realizada de acordo com equação (4) de Alcântara e Santos (2002):

$$
E T P=\frac{(V \cdot F c)}{P}
$$

Onde:

$\mathrm{P}=$ Precipitação média mensal $(\mathrm{m})$;

$V=$ Volume da unidade de paisagem $\left(\mathrm{m}^{3}\right)$;

$\mathrm{Fc}=$ Fator de correção $(\mathrm{m})$;

ETP = Evapotranspiração na unidade de paisagem $\left(\mathrm{m}^{3}\right)$.

O Fator de correção é atribuindo em função de cada unidade de paisagem. Dessa forma, área urbanizada foi de $1 \mathrm{~mm}$; solo exposto e área de vegetação rasteira de 5 $\mathrm{mm}$ e vegetação densa 30mm (ALCÂNTARA; SANTOS, 2002).

A determinação das infiltrações foi realizada a partir da verificação de como ela se comporta por unidades de paisagem, além de fazer parte da determinação do escoamento superficial e verificar como a variável contribui para a recarga dos aquíferos. Para seu cálculo se aplicou a equação (5) de Soiland Conservation Service (SCG) (1957):

$$
q=\frac{(Q . S)}{P}
$$

Onde:

$q=$ Volume infiltrado na unidade de paisagem $\left(\mathrm{m}^{3}\right)$;

$\mathrm{Q}=$ Precipitação efetiva $(\mathrm{m})$;

$\mathrm{S}=$ Coeficiente de armazenamento de água na camada superior do solo (adimensional);

$\mathrm{P}=$ Precipitação média mensal $(\mathrm{m})$. 
As precipitações efetivas correspondem a parcela da chuva que é capaz de gerar ou produzir escoamento em determinada região (GRAY, 1970). Por consequência, em cada unidade de paisagem foi calculada a precipitação efetiva. Para tanto, foram utilizadas as equações (6 e 7) de Kohler e Richards (1962):

$$
Q=\frac{(P-(0,2 . S))^{2}}{P+(0,8 . S)}
$$

Sendo:

$S=\underline{25400}-254$

$\mathrm{CN}$

Onde:

$\mathrm{Q}=$ Precipitação efetiva $(\mathrm{m})$;

$\mathrm{P}=$ Precipitação média mensal $(\mathrm{m})$;

$\mathrm{S}=$ Coeficiente de armazenamento de água na camada superior do solo (adimensional);

$\mathrm{CN}$ = Parâmetro de Adequação a Unidades de Paisagem (adimensional).

Nessas fórmulas são necessários à obtenção do coeficiente de armazenamento de água na camada superior do solo (s) (adimensional) e um parâmetro de adequação para diferentes unidades de paisagem, chamado Curve Number ou Número de Curva (CN) (adimensional). Esse número, de acordo com Tucci (2001) correlaciona à chuva eficaz e a chuva efetiva sendo determinado por consulta a valores tabelados, em função do tipo do solo, da umidade antecedente do solo (condições de umidade do solo anteriormente à ocorrência da precipitação que está sendo analisada), e do tipo de atividade/ocupação que é desenvolvida na bacia.

Cada tipo de solo possui seu determinado CN por utilização ou cobertura do solo. Assim, se calibrou, conforme Tucci (2001) os cálculos de escoamento superficial em função das unidades de paisagem e dos tipos de solo descritos pelo autor:

- Solos A: produzem baixo escoamento superficial e alta infiltração. Solos arenosos profundos com pouco silte e argila;

- Solos B: menos permeáveis do que o A. Solos arenosos menos profundos do que o tipo A e com permeabilidade superior à média;

- Solos C: geram escoamento superficial acima da média e com capacidade de infiltração abaixo da média, contendo porcentagem considerável de argila e pouco profundo;

- Solos D: contém argilas expansivas e pouco profundas com muito baixo escoamento superficial. 
ANÁLISE DE ASPECTOS HIDROLÓGICOS DAS SUB-BACIAS DO PARNAÍBA E ITAPECURU EM TIMON, MA

A partir de valores de $\mathrm{CN}$ para bacias hidrográficas urbanas e suburbanas defino por Tucci (2001), foram utilizados os seguintes parâmetros de adequação a unidades de paisagem: (i) área urbana, lotes com solo do tipo $\mathrm{C}(\mathrm{CN}=90)$; (ii) solo exposto, média entre o $\mathrm{CN}$ dos tipos $\mathrm{C}$ de bosques e cobertura ruim $(\mathrm{CN}=77)$, pastagens em más condições $(\mathrm{CN}=86)$ e terrenos baldios de terra $(\mathrm{CN}=80)$ resultando em $(C N=81)$; (iii) vegetação rasteira, média dos tipos $C$ do prado em boas condições $(C N=71)$ e de espaços abertos relvados em mais de $75 \%$ da área $(\mathrm{CN}=74)$ ocasionando em $(\mathrm{CN}$ = 73); (iv) vegetação densa (vegetação de médio e grande porte), florestais de cobertura boa, com tipo de solo $\mathrm{C}$ e $(\mathrm{CN}=70)$.

\section{RESULTADOS E DISCUSSÕES}

Os resultados da quantificação do escoamento superficial e dos valores da interceptação, evapotranspiração e infiltração para cada unidade de paisagem nas sub-bacias do Parnaíba e Itapecuru podem ser observados na Tabela 2 e 3

Tabela 2. Volume anual total das variáveis hidrológicas na sub-bacia do Itapecuru em Timon/MA

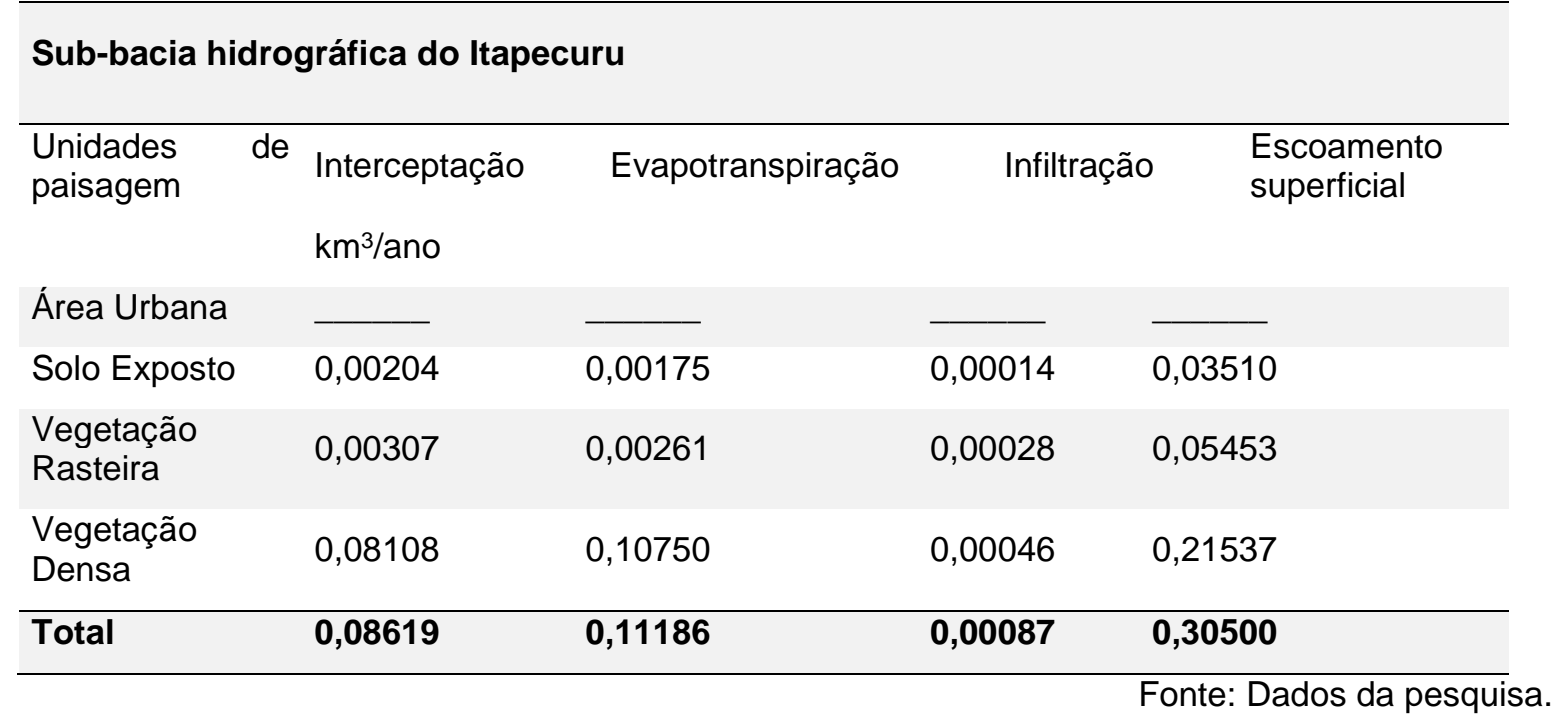


ANÁLISE DE ASPECTOS HIDROLÓGICOS DAS SUB-BACIAS DO PARNAÍBA E ITAPECURU EM TIMON, MA

Tabela 3. Volume anual total das variáveis hidrológicas na sub-bacia do Parnaíba em Timon/MA

\begin{tabular}{|c|c|c|c|c|}
\hline \multicolumn{5}{|c|}{ Sub-bacia hidrográfica do Parnaíba } \\
\hline $\begin{array}{l}\text { Unidades } \\
\text { paisagem }\end{array}$ & Interceptação & Evapotranspiração & Infiltração & $\begin{array}{l}\text { Escoamento } \\
\text { superficial }\end{array}$ \\
\hline \multicolumn{5}{|c|}{$\mathrm{km}^{3} / \mathrm{ano}$} \\
\hline Área Urbana & 0,00023 & 0,00031 & 0,00003 & 0,03441 \\
\hline Solo Exposto & 0,01440 & 0,01272 & 0,00014 & 0,26035 \\
\hline $\begin{array}{l}\text { Vegetação } \\
\text { Rasteira }\end{array}$ & 0,01542 & 0,01365 & 0,00028 & 0,27891 \\
\hline $\begin{array}{l}\text { Vegetação } \\
\text { Densa }\end{array}$ & 0,25597 & 0,33906 & 0,00046 & 0,68020 \\
\hline Total & 0,28602 & 0,36574 & 0,00091 & 1,25357 \\
\hline
\end{tabular}

A vegetação densa pertence ao bioma Cerrado com uma formação vegetal de Mata de Cocais, faixa transicional da Floresta Amazônica para a Caatinga (TIMON, 2014). Enquanto, a rasteira corresponde as áreas de regeneração, de atividades antrópicas, como a agricultura de subsistência, caracterizando-se como uma vegetação sucessional (TIMON, 2014). Presume-se também a destinação do uso do solo para a pecuária.

Monteiro e Silva Junior (2015) ao realizarem estudos de interceptação no bioma Cerrado constaram um valor de $26,4 \%$ em relação a participação pluviométrica, no entanto o volume aproximado da interceptação total $\left(0,37 \mathrm{~km}^{3} / \mathrm{ano}\right)$ de ambas as subbacias representam $27,46 \%$ da precipitação $\left(1,35 \mathrm{~km}^{3} / \mathrm{ano}\right)$ para o município de Timon. Isso significa que os volumes de interceptação podem variar em um mesmo ecossistema, entre fragmentos próximos ou até dentro de fragmentos da vegetação em virtude de seu estágio de sucessão (NICOLETTI, 2016).

Além disso, Monteiro e Silva Junior (2015) mencionam que existe uma escassez nos estudos dirigidos de interceptação da chuva pela vegetação no Cerrado, bem como da existência de variáveis que podem alterar interceptação nas microbacias, tais como fauna, da flora e de toda a bacia hidrográfica.

A área de abrangência da vegetação é um dos fatores dependentes da interceptação (BALBINOT et al., 2008; NICOLETTI, 2016). Nesse sentido, a área de vegetação densa corresponde a $69.15 \%$ de ocupação do município, enquanto a rasteira equivale a $15,11 \%$. Por isso, é possível verificar volumes superiores de interceptação da vegetação densa e rasteira na sub-bacia do Parnaíba em relação à Itapecuru. 
ANÁLISE DE ASPECTOS HIDROLÓGICOS DAS SUB-BACIAS DO PARNAÍBA E ITAPECURU EM TIMON, MA

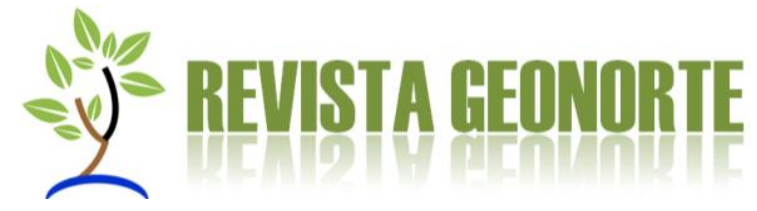

Ao comparar a cobertura vegetal densa com a rasteira de ambas as sub-bacias se constatam que as áreas equivalentes ao substrato arbóreo/arbustivo fechado possuem maiores capacidades de interceptação. Logo, uma vegetação de menor porte (gramíneas e as de culturas agrícolas e/ou de áreas em virtude do estágio de regeneração) apresenta uma capacidade inferior de interceptação, devido as folhagem e troncos (BALBINOT et al., 2008; MONTEIRO; SILVA JÚNIOR 2015). Outros aspectos que exercem influência na interceptação são as características da precipitação, condições climáticas, propriedades das folhas, como por exemplo, de acordo com Clarke e Tucci (1997) quanto maior for a superfície de folhagem, maior a área de retenção da água, e densidade da vegetação

A partir da superfície das folhas é que ocorre a evapotranspiração (PINTO et al., 2008). Como resultado, ocorreu o aumento do volume da evapotranspiração na medida em que de desloca da unidade de área urbana para a vegetação densa. $\mathrm{O}$ que proporciona as diferenças entre os volumes de evapotranspiração verificados nas Tabelas 2 e 3, e de como o fenômeno possui relações diretas com a densidade da cobertura vegetal.

De modo geral, a infiltração é diretamente proporcional à densidade da cobertura vegetal (BALBINOT et al., 2008). Considerando isso, são justificáveis que os volumes de infiltração das unidades de paisagem de vegetação rasteira nas sub-bacias sejam menores quando comparados com a densa, conforme as Tabelas 2 e 3. Com isso, a capacidade de infiltração nas coberturas vegetais de grande porte é maior (TUCCI; MENDES, 2006; NICOLETTI, 2016).

Além disso, infere-se que as áreas de vegetação rasteira possuem fins para atividades agropecuárias. Um dos principais impactos da produção animal ao solo é a sua compactação, alterando sua estrutura superficial ao criar uma camada mais densa na qual dificulta a infiltração da água (LEITE; SILVA; HENRIQUES, 2011).

Para as áreas de solo exposto, que corresponde a $11,84 \%$ da área do município (Tabela 1), os volumes de infiltração refletem que o solo totalmente sem cobertura vegetal sofre compactação através das gotas da chuva (LOMBARDI NETO; BERTONI, 2010). Dessa forma, ao confrontar os volumes de vegetação densa e rastreira, as áreas de solo exposto apresentam volumes menores de infiltração em ambas as sub-bacias, como observado nas Tabelas 2 e 3.

A infiltração na área urbana, presente somente na sub-bacia do Parnaíba, abrange apenas $1,78 \%$ da área do município (Tabela 1 ) e possui menor volume de infiltração, conforme verificado nas Tabelas 2 e 3 . Essa classe de unidade é caracterizada pela impermeabilização e compactação do solo, e remoção da cobertura vegetal decorrente dos processos de urbanização, o que explica seu baixo volume de infiltração (PINTO et al. 2008).

Desse modo, provoca um decréscimo na alimentação do nível freático, uma vez que para SCG (1957), a infiltração é responsável pela recarga dos aquíferos. Assim, infere-se que volume total de infiltração $\left(0,00091 \mathrm{~km}^{3} / \mathrm{ano}\right)$ é responsável pela recarga natural do aquífero Poti-Parnaíba, responsável por parte do abastecimento de água da cidade (CORREIA FILHO et al., 2011; TIMON, 2014). 
ANÁLISE DE ASPECTOS HIDROLÓGICOS DAS SUB-BACIAS DO PARNAÍBA E ITAPECURU EM TIMON, MA

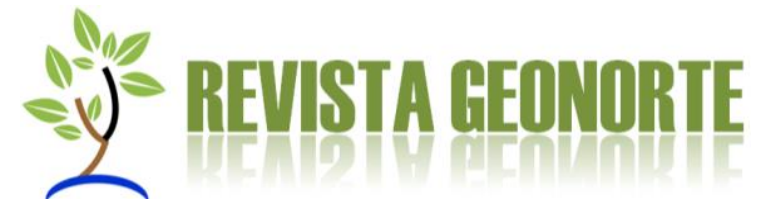

$\mathrm{Na}$ análise do escoamento superficial e infiltração, pode-se inferir alguma alteração antrópica no ciclo hidrológico, o que pode ocasionar problemas relacionados à recarga dos aquíferos, utilizados no abastecimento público de água da cidade de Timon. Consequentemente, os processos de urbanização, criam áreas impermeáveis que reduz a capacidade da infiltração do solo.

Logo, este volume retido na superfície aumenta o escoamento superficial diminuindo o nível do lençol freático por falta de alimentação (MENDES; TUCCI, 2006). Como resultado, os aumentos das áreas urbanas possibilitam interferências na produtividade natural da água, podendo causar valores menores de infiltração quando comparados ao superficial, considerando o tamanho da área analisada.

As condições de superfície do solo, infiltração e precipitação influenciam no escoamento superficial (COSTA et al., 2016). Torna-se, assim justificável a diferença dos volumes de escoamento superficial nas unidades de paisagem nas duas subbacias (ver Tabelas 2 e 3 ) ao admitir suas capacidades de infiltração e cobertura vegetal. O solo com cobertura vegetal densa apresentar maior volume de infiltração produzindo menores quantidades de escoamento superficial (TUCCI, MENDES, 2006;). Porém, os dados encontrados não correspondem ao afirmados pelos autores, isso pode ser em razão do tamanho da área da unidade de paisagem, uma vez que as de vegetação densa são as que possuem maior abrangência no município (ver Tabela 1).

Solos expostos, sobretudo, em virtude do desmatamento resultam em maiores escoamentos devido a compactação, bem como os que possuem pequena profundidade possuem influência no escoamento superficial devido a sua menor quantidade de drenagem de água (CLARKE, TUCCI, 1997; TUCCI, MENDES, 2006; PAZ, 2004). Nessa perspectiva, o município de Timon possui, principalmente, a associação de solos geralmente profundos (CORREIA FILHO et al., 2011). O que implica, de modo geral, serem suscetíveis ao escoamento superficial.

A área urbana da cidade é a de menor abrangência na sub-bacia do Parnaíba, por consequência possui o menor volume de escoamento superficial. Porém, a literatura especializada afirma que os processos de urbanização tendem a provocar o aumento do comportamento do escoamento superficial, devido a expansão da impermeabilização da cobertura da bacia hidrográfica e a construção de condutos pluviais (PAZ, 2004; TUCCI, MENDES, 2006).

\section{CONCLUSÕES}

De modo geral, observa-se que ainda há poucos estudos sobre o comportamento hidrológico nas porções da bacia hidrográfica do Parnaíba e Itapecuru no município de Timon, bem como para um manejo de seus recursos hídricos. Logo, o estudo apesar de suas limitações, como por exemplo, a ausência de uma estação pluviométrica no município para determinações mais precisas da precipitação, serviu para compreender, de modo geral, o funcionamento hidrológico das sub-bacias do Parnaíba e Itapecuru em Timon. 
ANÁLISE DE ASPECTOS HIDROLÓGICOS DAS SUB-BACIAS DO PARNAÍBA E ITAPECURU EM TIMON, MA

Os resultados do estudo sobre os volumes hidrológicos dimensionados nas subbacias no município de Timon permitem perceber como a cobertura vegetal exerce papel fundamental na interceptação, evapotranspiração, infiltração e escoamento superficial nas bacias hidrográficas.

A sub-bacia do Itapecuru apresenta menor extensão em comparação com a de Parnaíba, porém os comportamentos hidrológicos em ambas ocorrem de maneira semelhante nas unidades de paisagem de vegetação densa, rasteira e solo exposto. Além disso, foi verificado que somente a sub-bacia do rio Parnaíba possui uma área urbanizada com possíveis alterações no escoamento e infiltração na região.

O estudo também ressalta o qual importante é a determinação das variáveis do comportamento hidrológico de uma bacia hidrográfica. Entender isso implica na necessidade de realizar pesquisas sobre a disponibilidade hídrica natural. Por isso, os monitoramentos de seus aspectos hidrológicos devem ser constantes, para haver um planejamento de recursos hídricos adequado em ambas as sub-bacias do município.

\section{REFERÊNCIAS}

ALCÂNTARA, E.H; SANTOS, M. C. F. V. Metodologia para estudos básicos em hidrologia aplicados a pequenas bacias hidrográficas. UFMA. São Luís, 2002.

BALBINOT, R. et al. O papel da floresta no ciclo hidrológico em bacias hidrográficas. Ambiência, Guarapuava, PR. v.4, n.1, p.131-149, jan./abr., 2008.

BLAKE, G.J. The interception process. In: T.G. Chapman and F.X. Dunin (eds.). Prediction in Catchment Hydrolgy. Australian Academy of Science, Canberra, p. 59$81,1975$.

BRASIL. Agência Nacional de Águas. Conjuntura dos recursos hídricos no Brasil: regiões hidrográficas brasileiras. Brasília: ANA, 2015.

CLARK, O. R. Interception of rainfall by grasses weeds and certain crop plants. Ecological Monographs. v.10, n. 2, p. 243-277, 1940.

CLARKE, R. T.; TUCCI, C. E. M. Impacto das mudanças da cobertura vegetal no escoamento: revisão. Revista Brasileira de Recursos Hídricos. v. 2, n. 1, jan./jun., p. 135-152, 1997.

CORREIA FILHO, F. L. et al. Projeto Cadastro de Fontes de Abastecimento por Água Subterrânea, estado do Maranhão: relatório diagnóstico do município de Timon. Teresina: CPRM, 2011.

COSTA, C. D. O. et al. Produção e deposição de sedimentos em uma sub-bacia hidrográfica com solos suscetíveis à erosão. Irriga, Botucatu. v. 21, n. 2, p. 284-299, maio/jun., 2016. 
ANÁLISE DE ASPECTOS HIDROLÓGICOS DAS SUB-BACIAS DO PARNAÍBA E ITAPECURU EM TIMON, MA

CUNHA, J. E. B. L. et al. Dinâmica sazonal da cobertura do solo em uma região semiárida e seus impactos no ciclo hidrológico. Revista Brasileira de Recursos Hídricos. v, 19, n. 2, p. 197-207, abr./jun.,2014.

GRAY, D. M. Handbook of the principles of hydrology. Huntington: Waterlnformation Center. 1970.

INSTITUTO BRASILEIRO DE GEOGRAFIA E ESTATÍSTICA (IBGE/Cidades). Dados da população estimada e área da unidade territorial e mapas. 2017. Disponível em: <http://www.cidades.ibge.gov.br > Acesso em: 30 de jun. 2017.

INSTITUTO NACIONAL DE METEOROLOGIA (INMET). Banco de dados meteorológicos para ensino e pesquisa (BDMEP). Disponível em: <http://www.inmet.gov.br/projetos/redes/pesquisa/>. Acesso em: 16 de jan. 2016.

KOHLER, M.A; RICHARDS, M. M. Multi-Capacity Basin Accounting for Predicting Runofffrom Storm Precipitation. Journal of Geophysical Rosearch. Washington, p. 5187-97, 1962.

LEITE, S. P.; SILVA, C. R.; HENRIQUES, L. C. Impactos ambientais ocasionados pela agropecuária no complexo Aluízio Campos. Revista Brasileira de Informações Científicas. v.2, n.2, p.59-64. 2011.

LOMBARDI NETO, F.; BERTONI, J. Conservação do solo. 7. ed. São Paulo: Ícone Editora, 2010.

MARQUES, R. J. Considerações acerca dos processos erosivos: uma abordagem teórica preliminar em áreas urbanas em Timon, MA. In: JORNADA DE ESTUDOS DE GEOGRAFIA FÍSICA, 3., 2015. Teresina. Anais...Teresina, UFPI, 2015.

MONTEIRO, B. G.; SILVA JUNIOR, J. L. C. Precipitação efetiva e interceptação no bioma Cerrado em uma microbacia experimental. Agri. Environmental Sciences. v. 1. n. 3, p.50-54, 2015.

NICOLETTI, A. L. Interceptação e escoamento superficial em diferentes estágios de regeneração em floresta ombrófila densa na Mata Atlântica. 2016. 104f. Dissertação (Mestrado em Engenharia Florestal). Universidade Regional de Blumenau. Blumenau, 2016.

PAZ, A. R. Hidrologia Aplicada. Universidade Estadual do Rio Grande do Sul, Caxias do Sul, 2004.

PINTO, N. L. S.; et al. Hidrologia básica. 11. ed. São Paulo: Edgard Blucher, 2008.

SEBUSIANI, H. R. V.; BETTINE, S. C. Metodologia de análise do uso e ocupação do solo em micro bacia urbana. G\&DR. Taubaté, SP, Brasil, v. 7, n. 1, p. 256-285, jan./abr., 2011. 
ANÁLISE DE ASPECTOS HIDROLÓGICOS DAS SUB-BACIAS DO PARNAÍBA E ITAPECURU EM TIMON, MA

SILVA. M. S. Crescimento urbano e degradação ambiental: a ausência de espaços livres no Residencial Novo Tempo em Timon-MA. 108 f. 2016. Dissertação (Mestrado em Práticas em Desenvolvimento Sustentável). Universidade Federal Rural do Rio de Janeiro. Rio de Janeiro, 2016.

SOIL AND CONSERVATION SERVICE (SCS). Engineering Handbook: Section 4, Hydrology. Supplement A. United States Department of Agriculture. Washington, D.C, 1957.

TIMON. Secretaria Municipal de Planejamento. Plano Municipal de Saneamento Básico (PMSB). Timon, 2014.

TUCCI, C. E. M. Hidrologia: ciência e aplicação. 2. ed. Porto Alegre: UFRGS, 2001.

TUCCI, C. E. M.; MENDES, C. A. Avaliação ambiental integrada de bacia hidrográfica. Brasília: MMA, 2006.

VAEZA, R. F. et al. Uso e ocupação do solo em bacia hidrográfica urbana a partir de imagens orbitais de alta resolução. Floresta e Ambiente, v. 17, n.1, p.23-29, 2010. 